Int. J. Dev. Biol. 54: 1-6 (2010)

doi: $10.1387 / \mathrm{ijdb} .082727 \mathrm{dr}$

\title{
The contribution of Roberto Montesano to the study of interactions between epithelial sheets and the surrounding extracellular matrix
}

\author{
DOMENICO RIBATTI* \\ Department of Human Anatomy and Histology, University of Bari Medical School, Bari, Italy
}

\begin{abstract}
The interactions between epithelial cells and the surrounding extracellular matrix are a central issue in morphogenesis studies. Roberto Montesano and colleagues at the University Medical Center of Geneva, Switzerland, have extensively investigated the mechanisms underlying two morphogenetic processes: the formation of new capillary blood vessels from pre-existing ones (angiogenesis) and the generation of branching epithelial tubules (tubulogenesis), which are crucial events in the development of most parenchymal organs. Dr. Montesano has contributed to clarifying some cellular and molecular mechanisms of angiogenesis and tubulogenesis using an original three-dimensional cell culture system which replicates key events of angiogenesis and tubulogenesis, thereby facilitating molecular analysis. A major advance of this technique over conventional monolayer cultures is that cells can be embedded within a lattice of reconstituted collagen fibrils which mimics the three-dimensional organization of connective tissue matrices. The results of these studies support the notion that cell interactions with the surrounding extracellular matrix are crucial determinants of cell responses to growth factors and that epithelial tissues morphogenesis is governed by the interplay of two different classes of signaling molecules, i.e. paracrine-acting growth factors and insoluble extracellular matrix components.
\end{abstract}

KEY WORDS: angiogenesis, epithelial tissue, extracellular matrix, morphogenesis, tubulogenesis

\section{Introduction}

The interactions between epithelial cells and the surrounding extracellular matrix (ECM) are a central issue in research on morphogenesis. Since the studies by Grobstein (1954), it has become increasingly clear that the ECM serves not only as an inert physical scaffolding for the developing tissues, but also provides environmental signals to the cells involved, playing a guiding role in morphogenetic processess. Moreover, the ECM is the natural substratum through which various cell types migrate during embryogenesis.

Different epithelia, such as those of the thyroid follicles, kidney tubules, and the branching ducts in the lung and exocrine glands, acquire diverse forms correlated to their specific functions. The development of most glandular organs begins with the invagination of an existing epithelial sheet into the underlying mesenchyma. The primary bud thus generated subsequently undergoes a series of morphogenetic events that culminate in the formation of branching tubes (excretory ducts) and hollow spheres (follicles, alveoli, acini). A number of studies have led to the identification of mesenchyme-derived diffusible messengers that promote the elongation and branching of epithelial tubes.

In the last thirty years, working at the University Medical Center of Geneva, Switzerland, Roberto Montesano (Fig. 1) has extensively investigated the mechanisms underlying two morphogenetic processes: the formation of new capillary blood vessels from pre-existing ones (angiogenesis) and the generation of branching epithelial tubules (tubulogenesis), which are crucial events in the development of most parenchymal organs.

\footnotetext{
Abbreviations used in this paper: bFGF, basic fibroblast growth factor; ECM, extracellular matrix; EMT, epithelial mesenchymal transition; FCS, fetal calf serum; HGF, hepatocyte growth factor; MDCK, Madin Darby canine kidney; MMP-9, matrix metalloproteinase-9; PMA, phorbol myristate acetate; PAs, plaminogen activators; PAI-1, plasminogen activator inhibitor-1; RA, retinoic acid; TNF- $\alpha$, tumor necrosis factor alpha; TGF- $\beta 1$, transforming growth factor beta 1; UPAR, urokinase plasminogen activator receptor; VEGF, vascular endothelial growth factor.
}

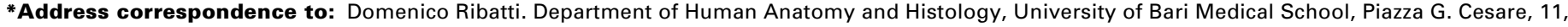
Policlinico, 70124 Bari, Italy. Fax.+39-080-547-8310. e-mail: ribatti@anatomia.uniba.it
} 


\section{Mechanisms underlying angiogenesis}

The term angiogenesis, applied to the formation of capillaries from pre-existing vessels, i.e. capillaries and post-capillary venules, is based on endothelial sprouting or intussusceptive (non-sprouting) microvascular growth (Risau, 1997; Burri and Tarek, 1990). During angiogenesis, microvascular endothelial cells focally degrade their investing basement membrane, and subsequently migrate into the interstitial matrix of the surrounding connective tissue (Ausprunk and Folkman, 1977). The sprout elongates by further migration and by endothelial cell proliferation proximal to the migrating front, and a lumen is gradually formed proximally to the region of proliferation. Contiguous tubular sprouts anastomose to form functional capillary loops, and vessel maturation is accomplished by means of reconstitution of the basement membrane (Ausprunk and Folkman, 1977).

Under physiological conditions, angiogenesis is dependent on the balance of positive and negative angiogenic modulators within the vascular microenvironment (Hanahan and Folkman, 1996), and requires the functional activities of a number of molecules, including angiogenic factors, extracellular matrix proteins, adhesion receptors and proteolytic enzymes. As a consequence, angiogenic endothelial cells have a distinct gene expression pattern, that is characterized by a switch of the cell proteolytic balance towards an invasive phenotype, as well as by the expression of specific adhesion molecules (Pepper et al., 1996).

The process of angiogenesis remained largely inaccessible to experimental analysis until the development of bioassays for angiogenesis during the 1970s. These included the long-term culture of vascular endothelial cells, the development of the chick embryo chorioallantoic membrane and in vivo rabbit/murine assays. These assays have been used to describe the morphological events occurring in angiogenesis, to identify stimulators and inhibitors of angiogenesis, and to quantitate the neovascular response to test compounds.

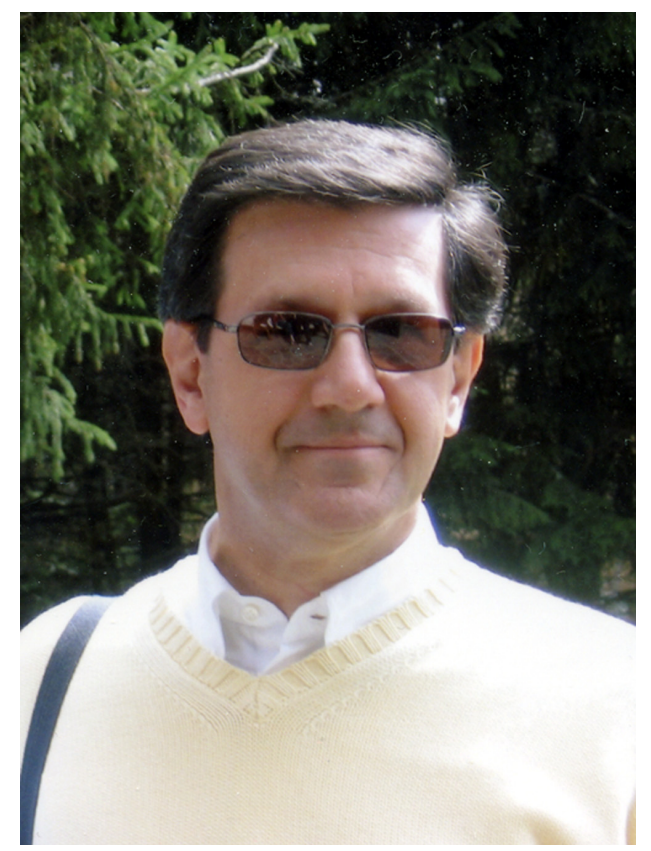

Fig. 1. A portrait of Dr. Roberto Montesano (courtesy of Dr. Montesano).

\section{Collagen matrix promotes the organization of endothe- lial cells into capillary-like tubules and the induction of the invasive phenotype}

In 1983, Montesano and co-workers demonstrated that when a monolayer of microvascular endothelial cells on the surface of a collagen gel is covered with a second layer of collagen, it reorganizes within a few days into a network of branching and anastomosing tubules, without invading the underlying matrix, demonstrating that a three-dimensional interaction with collagen fibrils plays an important role in driving capillary morphogenesis (Montesano et al., 1983).

Next, Montesano and co-workers demonstrated that when confluent monolayers of microvascular endothelial cells on collagen gels were treated with phorbol myristate acetate (PMA), a tumor promoter that markedly stimulated the production of collagenase and plasminogen activators (Pas), whereas control endothelial cells were confined to the surface of the gels, PMAtreated endothelial cells invaded the underlying collagen matrix, where they formed capillary-like tubular structures (Montesano and Orci, 1985). This experimental sytem has become a widely used in vitro assay of angiogenesis (reviewed in Vailhé et al., 2001) and the underlying mechanisms have been investigated in detail by the group of George Davis. More recent studies have revealed that genes regulating the matrix-integrin-cytoskeletal signaling axis are differential expressed during endothelial cell morphogenesis. It has been demonstrated that endothelial cells interactions with extracellular matrices establish signaling cascade downstream of integrin ligation leading to activation of the Rho GTPase, CDC42 and Rac1, which are required for lumen formation (reviewed in Davis et al., 2007). Current research analyze how specific molecules integrate signaling information to induce endothelial cell lumen formation, pericyte recruitment and stabilization processes to control vascular morphogenesis.

Montesano and co-workers demonstrated that also the basic fibroblast growth factor (bFGF) induced the endothelial cells to invade the underlying collagen matrix and to form capillary-like tubules, and stimulated the endothelial cells to produce PAs (Montesano et al., 1986). These data, together with other evidence gained at the Montesano lab demonstrating an increased UPA and urokinase plasminogen activator receptor (UPAR) expression in endothelial cells migrating from the edge of an experimental wound in vitro (Pepper et al., 1987; Pepper et al., 1993 a), supported the role of the PA/plasmin system in angiogenesis.

In 1992, Montesano and co-workers demonstrated that the vascular endothelial growth factor (VEGF) induces microvascular endothelial cells grown on collagen gels to invade the underlying matrix, where they form capillary-like tubules (Pepper et al., 1992) (Fig. 2). Moreover, when added simultaneously, VEGF and bFGF induced an in vitro angiogenic response which was greater than the sum of the two, and which occurred with greater rapidity than the response to either cytokine alone (Pepper et al., 1992 a). These results demonstrate that, by acting in concert, these two cytokines have a potent synergistic effect on the induction of angiogenesis in vitro.

In 1993, Montesano and co-workers demonstrated a biphasic action of transforming growth factor beta- 1 (TGF- $\beta 1$ ) on in vitro angiogenesis: at low concentrations it decreased bFGF- or VEGF- 


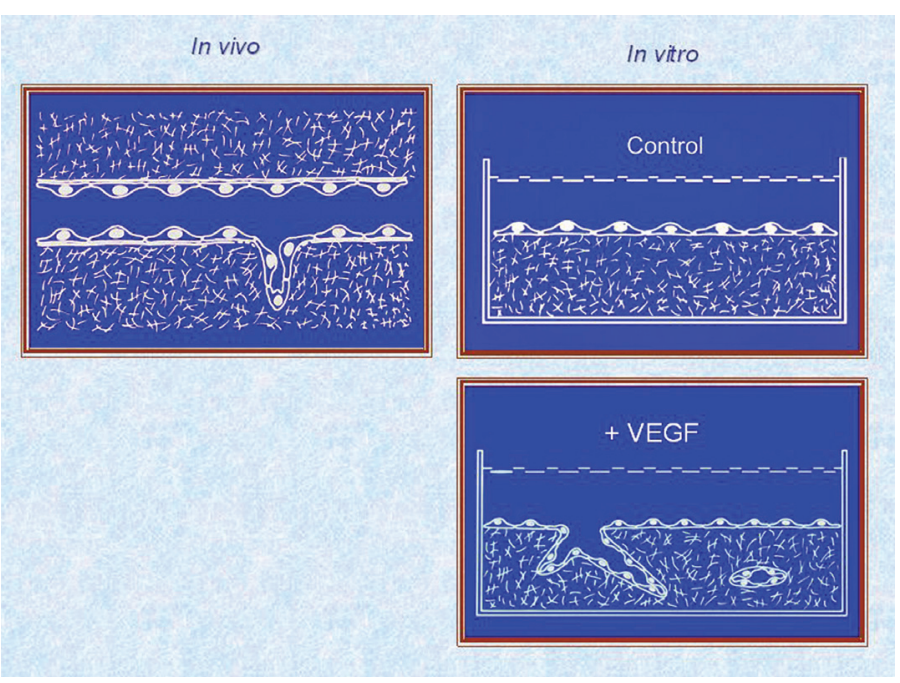

Fig. 2. A scheme of the three dimensional cell culture system showing that VEGF induces microvascular endothelial cells grown on collagen gels to invade the underlying matrix (courtesy of Dr. Montesano).

induced invasion, whereas at high concentrations it increased invasion (Pepper et al., 1993 b). At the TGF- $\beta 1$ concentration which potentiates bFGF- or VEGF-induced invasion, an optimal balance between proteases and protease inhibitors may be achieved at the cell surface, which allows focal pericellular matrix degradation, while at the same time protecting the matrix against excessive degradation (Pepper et al., 1994).

\section{Unbalanced proteolysis results in aberrant vascular morphogenesis}

In 1990, Montesano and co-workers developed an in vitro model of endothelioma formation by embedding middle-T oncogene-expressing endothelial cells into three-dimensional fibrin gels. In contrast to normal endothelial cells, which formed a network of capillary-like tubules, middle-T-expressing endothelial cells formed large cyst-like structures which resembled the endotheliomas observed in vivo(Montesano et al., 1990). When studying the proteolytic properties of middle-T-expressing endothelial cells, Montesano and co-workers found that these cells displayed increased PA activity when compared to non-middle-T-oncogeneexpressing endothelial cells, and this could be accounted for by an increase in UPA and a decrease in plasminogen activator inhibitor-1 (PAI-1) activity (Montesano et al., 1990). Finally, they found that when serine protease inhibitors were added to the cultures, the middle-T-expressing endothelial cells, instead of forming cysts, now formed branching capillary-like tubules (Montesano et al., 1990). Overall, these data demonstrated that an excessive proteolytic activity is not compatible with normal capillary morphogenesis, but that by reducing this activity through the addition of protease inhibitors, normal morphogenetic properties can be restored.

\section{Mechanisms underlying tubulogenesis}

The formation of branched tubes from initially unbranched epithelial buds is a fundamental morphogenetic process in the development of many organs, including the pancreas, liver, mammary gland, lung and kidney (Affolter et al., 2003; Lubarsky and Krasnow, 2003). In vivo, this complex process relies on the interaction of different cell types and various environmental factors, resulting in tubular structures that contain multiple cell types with different functions. Tubules can arise through two main mechanisms: the invagination of cells from an epithelial sheet, as occurs in the formation of the neural tube or through the organization of initially unpolarized cells into cord-like structures that invade the surrounding mesenchyme, forming branched, hollow tubules lined by polarized cells (Hogan and Kolodziej, 2002). Using tissue dissociation techniques, it has been demonstrated that the embryonic epithelia fail to undergo branching morphogenesis if separated from the adjacent mesenchyme, and that morphogenesis resumes when the components are recombined in vitro.

Elucidation of the mechanisms responsible for epithelial tubulogenesis is a complex task in view of the myriad, complex cell interactions occurrring in vivo, involving the concerted action of a number of external positive and inhibitory stimuli including various growth factors and ECM components.

\section{Fibroblast-derived soluble factors induce morphogen- esis of branching tubules by kidney epithelial cells}

Montesano and co-workers investigated whether the morphogenetic properties of the Madin-Darby canine kidney (MDCK) cells might be influenced by diffusible factors released by neighbouring mesenchymal or stromal cells. MDCK cells have been shown to retain several anatomical and functional properties of the kidney distal tubule or collecting duct epithelium, and to generate tubule-like structures in vivo. When grown within threedimensional collagen gels, MDCK cells form spherical cysts (McAteer et al., 1987).

Montesano and co-workers demonstrated that: 1) MDCK cells suspended within a collagen gel contiguous to a fibroblastpopulated gel layer form branching tubules instead of the spherical cysts that develop in the absence of fibroblasts; 2) MDCK cells grown as a monolayer on a cell-free collagen gel cast layer invade the underlying collagen matrix, within which they form a network of branching tubules; 3) fibroblast-conditioned medium mimics the effect of co-culture by eliciting tubule formation by MDCK cells (Montesano et al., 1991 a).

\section{Hepatocyte growth factor is a paracrine mediator of morphogenetic epithelial-mesenchymal interactions in MDCK cells}

With the aim of identifying the factor which mediates the tubulogenic effect of fibroblast conditioned media, Montesano and co-workers demonstrated that: 1) MDCK cells grown in collagen gels in the presence of the hepatocyte growth factor (HGF) formed linear or branching tubular structures; 2) MDCK cells grown in the presence of fibroblast-conditioned medium that had been preincubated with specific anti-HGF antibodies exclusively formed spherical cysts similar to those observed in the absence of conditioned medium; 3) anti-HGF antibodies suppressed tubulogenesis in co-cultures of MDCK cells and fibroblasts (Montesano et al., 1991 b). Overall, these data demon- 
strated that the fibroblast-derived factor that induces tubule formation by MDCK cells is HGF.

HGF is a pleiotropic factor, capable of inducing cell motility, proliferation, anchorage-independent growth and morphogenesis. It was identified as the fibroblast growth factor that stimulates epithelial cells derived from a variety of different organs to form tubule-like extensions when seeded in three-dimensional matrices (Weidner et al., 1993; Brinkmann et al., 1995).

The epithelial morphogenesis assay developed by $R$. Montesano has been utilized by many investigators to dissect the mechanisms of HGF-induced tubulogenesis. These tubes can form elaborate networks in the lung, kidney, reproductive organs and vascular tree, as well as the many glands branching from the digestive tract, such as the liver, pancreas and salivary glands. In particular, a thorough analysis of this phenomenon by the group of Keith Mostov has provided a detailed documentation of the sequential steps involved and has demostrated the requirement for partial and transient epithelial mesenchymal transition (EMT) in the tubulogenic process (reviewed in O'Brien et al., 2002; Zegers et al., 2003). These Authors proposed that growth factors such as HGF promote tubular development by inducing a transient, partial EMT that alters the arrangement of cells at the onset of the three-surface pursuit.

The role of the transcription factor Snail in modulation of permeability and tight junction proteins in MDCK cells

Montesano and co-workers investigated the role of the transcription factor Snail on epithelial properties of MDCK cells

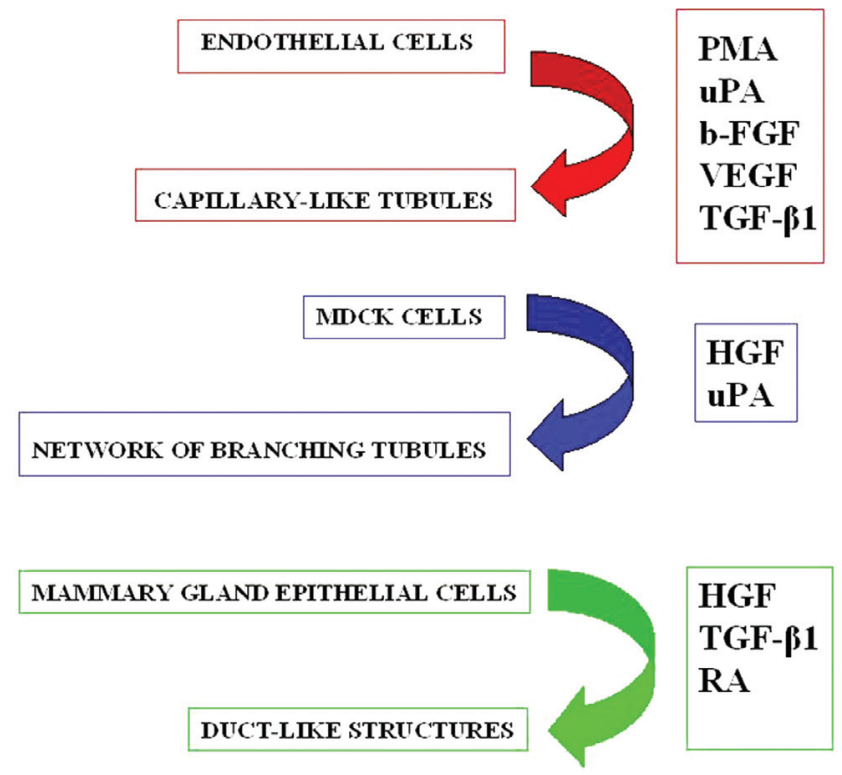

Fig. 3. Principal factors studied by Roberto Montesano and collaborators. Schematic drawing of molecules involved in angiogenesis and tubulogenesis of Madin-Darby canine kidney (MDCK) cells and mammary epithelial cells by using an original three-dimensional cell culture system. Abbreviations: PMA, phorbol myristate acetate; UPA, urokinase plasminogen activator; bFGF, basic fibroblast growth factor; VEGF, vascular endothelial growth factor; TGF- $\beta 1$, transforming growth factor beta 1; $H G F$, hepatocyte growth factor; $R A$, retinoic acid.
(Carrozzino et al., 2005). To this purpose, they expressed mouse Snail cDNA in MDCK cells with a tetracycline-inducible expression system with the aim to identify novel downstream targets of Snail. They demonstrated the induciblle expression of Snail does not result in overt EMT, but selectively reduces the expression of claudin-3, -4 and -7 and parallely increases paracellular ionic conductance without affecting tight junction permeability to uncharged solutes (Carrozzino et al., 2005). Overall, these data suggest that in addition to its well established role in EMT during enbryogenesis and tumor progression, Snail may act as a regulator of epithelial permeability.

\section{Epithelial tubulogenesis is dependent on extracellular plasmin-dependent proteolysis}

Montesano and co-workers observed that when MDCK cells were grown in fibrin gels instead of collagen gels, HGF-induced tubule formation was prevented by the addition of serine proteinase inhibitors (Montesano et al., 1991 a). Moreover, Montesano and co-workers found that: 1) conditioned medium from MCR-5 fibroblasts increased uPA activity and mRNA by about 5 -fold and this effect was completely inhibited by preincubation of conditioned medium with anti-HGF antibodies; 2) exogenously added recombinant $\mathrm{HGF}$ induced a comparable increase in UPA activity and mRNA in MDCK cells; 3 ) both MRC-5-conditioned medium and HGF induced a more than 30-fold increase in UPAR mRNA in MDCK cells (Pepper et al., 1992 b). Overall, these data suggest that epithelial tubulogenesis is dependent on extracellular plasmin-dependent proteolysis, which results from a concomitant increase in UPA and UPAR expression.

\section{Paracrine epithelial-mesenchymal interactions induce tubulogenesis in other types of epithelial cells}

Montesano investigated the mechanisms underlying tubulogenesis and lumen formation in the mammary gland, which is one of the few organs that undergo cycles of growth, morphogenesis, differentiation, functional activity, and involution in postnatal life (Daniel and Silberstein, 1987).

Firstly, Montesano and co-workers investigated whether diffusible factors released by fibroblasts could promote the formation of duct-like structures by mammary gland epithelial cells embedded in collagen gels. They used a mammary gland-derived cell line (TAC-2) and found that fibroblast-conditioned medium stimulated the development of an extensive system of highly arborized duct-like structures (Soriano et al., 1995). Moreover, the effect of fibroblast-conditioned medium was completely abrogated by antibodies to HGF, whereas the addition of exogenous HGF to the cultures mimicked the tubulogenic activity of conditioned medium. Finally, the effect of HGF was markedly boosted by the simultaneous addition of hydrocortisone, which also enhanced lumen formation (Soriano et al., 1995).

\section{HGF and TGF- $\beta 1$ play a role in mammary gland morpho- genesis in vivo}

Montesano and co-workers studied the expression of HGF and its receptor, c-met, in the rat mammary gland during pregnancy, lactation and involution (Pepper et al., 1995). They demonstrated 
that the levels of both HGF and c-met mRNA progressively reduced during pregnancy, were undetectable during lactation, but increased during the involution phase up to prepregnancy levels. Moreover, after 3 days of lactation both HGF and c-met transcripts were once again reduced to undetectable levels in the mothers. Finally, because the levels of HGF/c-met were inversely correlated with the levels of prolactin, Montesano and co-workers investigated the effects of prolactin on c-met expression in TAC2 cells. They demonstrated that prolactin significantly reduced the levels of c-met mRNA in TAC-2 cells, thus providing a possible mechanism for c-met downregulation in the rat mammary gland during lactation.

Montesano and co-workers demonstrated that low concentrations of TGF- $\beta 1$ promote the elongation and branching of TAC-2 cells, whereas high levels have inhibitory effects (Soriano et al., 1996). They employed an in vitro system in which J3B1A mammary epithelial cells grown in collagen gels in chemically defined medium form spherical cysts. Montesano and co-workers demonstrated that the addition of acidified fetal calf serum (FCS) to the defined medium induced the formation of branching tubes (Montesano et al., 2007). Using a pharmacological inhibitor of TGF- $\beta$ receptor signaling and a neutralizing antibody to TGF- $\beta 1$, Montesano and co-workers identified the active component in acidified FCS as TGF- $\beta 1$. Moreover, the effect of acidified FCS was replicated by the addition of exogenous TGF- $\beta 1$. Overall, these findings demonstrate that, at low concentrations, TGF- $\beta 1$ can activate a morphogenetic program resulting in the formation of epithelial tubes. To elucidate the mechanisms responsible for TGF- $\beta 1$-induced tubulogenesis, Montesano and co-workers assessed the effect of TGF- $\beta 1$ on the production of the matrix metalloproteinases (MMP) involved in collagen turn-over, and demonstrated a dose-dependent increase in matrix metalloproteinase-9 (MMP-9) following TGF- $\beta 1$ treatment. Tube formation was suppressed by a synthetic broad-spectrum MMP inhibitor, by a recombinant tissue inhibitor of MMP-2 and by a selective inhibitor of MMP-9, indicating that this morphogenetic process requires the activity of MMP-9.

\section{Retinoids induce lumen formation, whereas tumor ne- crosis factor alpha and bone morphogenetic protein-4 confer an invasive and transformed phenotype to cul- tured mammary epithelial cells}

Montesano and Soulié (2002) demonstrated that retinoic acid induces the formation of lumen-containing colonies (cysts) in cultured mammary epithelial cells. Moreover, using gelatin zymography, they observed a dose-dependent increase in the latent and active forms of MMP-9 following retinoic acid treatment. Finally, lumen formation was abrogated by the addition of the synthetic MMP inhibitor BB94, indicating that this morphogenetic process likely requires MMP activity.

Montesano and co-workers reported that tumor necrosis factor alpha (TNF- $\alpha$ ) causes multicellular colonies of mammary epithelial cells to disaggregate and induces cells grown on top of a collagen gel to invade the underlying matrix (Montesano et al., 2005). Moreover, they showed that TNF- $\alpha$ confers to mammary epithelial cells several additional properties that are characteristics of malignantly transformed cells, including proliferation in the absence of exogenously added growth factors, anchorage-inde- pendent growth and the loss of contact-mediated inhibition of proliferation (Montesano et al., 2005). These data provide a mechanistic basis for the reported ability of TNF- $\alpha$ to promote tumor progression and cancer cell dissemination (Szlosarek and Balkwill, 2003).

More recently, Montesano reported that bone morphogenetic protein 4 disrupts cyst organization in a concentration-dependent manner, causing lumen obliteration, the extension of invading cell cords, and three-dimensional cell scattering (Montesano, 2007). Montesano concluded that these bone morphogenetic protein-4induced biological responses may play a role in the progression of breast cancer.

\section{Concluding remarks}

Epithelial-mesenchymal interactions are inductive interactions occurring among cells or tissues of the same or a different embryonic origin. In specific developing settings, epithelial cells can transiently lose cell-cell adhesion and exhibit a migratory behavior (Hay, 1995). The process by which polarized epithelial cells are converted into motile cells is called the EMT (Eguchi and Kodama, 1993).

Tubulogenesis is a complex cellular response that requires the interplay of growth factors signaling induced by adhesion to the ECM and neighbouring cells. The ECM does not only serve as an inert physical scaffolding for the developing tissues, and the notion that ECM components mediate, at least in part, the inducing effect of mesenchyme on epithelial morphogenesis is now supported by a large body of experimental evidence.

Dr. Montesano has contributed to clarify some cellular and molecular mechanisms of angiogenesis and tubulogenesis, using an original three-dimensional cell culture system that replicates key events of angiogenesis and tubulogenesis, thereby facilitating molecular analysis (Fig. 3). A major advance of this technique over conventional monolayer cultures is that cells can be embedded within a lattice of reconstituted collagen fibrils, and it mimics the three-dimensional organization of connective tissue matrices.

The results of these studies support the notion that cell interactions with the surrounding ECM are crucial determinants of cell responses to growth factors and that epithelial tissues morphogenesis is governed by the interplay of two different classes of signaling molecules, i.e. paracrine-acting growth factors and insoluble ECM components.

\section{Acknowledgements}

Supported in part by MIUR (PRIN 2007), Rome, and Fondazione Cassa di Risparmio di Puglia, Bari, Italy.

\section{References}

AFFOLTER, M., BELLUSCI, S., ITOH, N., SHILO, B., THIERY, J.P. and WERB, Z (2003). Tube or not tube: remodeling epithelial tissues by branching morphogenesis. Dev Cel/ 4: 11-18.

BRINKMANN, V., FOROUTAN, H., SACHS, M., WEIDNER, K.M. and BIRCHEIMER, W. (1995). Hepatocyte growth factor/scatter factor induces a variety of tissuespecific morphogenetic programs in epithelial cells. J Cel/ Bio/131: 1573-1586.

BURRI, P.H. and TAREK, M.R. (1990). A novel mechanism of capillary growth in the rat pulmonary microcirculation. Anat Rec 228: 35-45.

CARROZZINO, F., SOULIE', P., HUBER, D., MENSI, N., ORCI, L., CANO, A., FEEAILLE, E. and MONTESANO, R. (2005). Inducible expression of Snail 


\section{D. Ribatti}

selectively increases paracellular ion permeability and differentially modulates tight junction proteins. Am J Physiol Cell Physio/289: C1002-C1014.

DANIEL, C.W. and SILBERSTEIN, G.B. (1987). Postnatal development of the rodent mammary gland. In The mammary gland(Ed. Neville, M.C. and Daniel, C.W.). Plenum Press, New York, pp. 33-36.

DAVIS, G.E., KOK, W. and STRATMAN, A.N. (2007). Mechanisms controlling human endothelial lumen formation and tube assembly in three-dimensional extracellular matrices. Birth Def. Res. 82: 270-285.

EGUCHI, G. and KODAMA, R. (1993). Transdifferentiation. Curr Opin Cel/ Bio/5: 1023-1028.

GROBSTEIN. C. (1954). Tissue interaction in the morphogenesis of mouse embryonic rudiments in vitro. In Aspects of Synthesis and Order in Growth (Ed. Rudnick, G.), Princeton University Press, Princeton, pp. 233-256.

HANAHAN, D. and FOLKMAN, J. (1996). Patterns and emerging mechanisms of the angiogenic swithc during tumorigenesis. Cel/86: 353-364.

HAY, E.D. (1995). An overview of epithelio-mesenchymal transformation. Acta Anat 154: 8-20.

HOGAN, B.L. and KOLODZIEJ, P.A. (2002). Organogenesis: molecular mechanisms of tubulogenesis. Nat Rev Genet 3: 513-523.

LUBARSKY, B. and KRASNOW, M.A. (2003). Tube morphogenesis: making and shaping biological tubes. Cel/112: 19-28.

MCATEER, J.A., EVAN, A.P. and GARDNER, K.D. (1987). Morphogenetic clonal growth of kidney epithelial cell line MDCK. Anat Rec 217: 229-239.

MONTESANO, R., ORCI, L. and VASSALLI, P. (1983). In vitro rapid organization of endothelial cells into capillary-like networks is promoted by collagen matrices. $J$ Cell Bio/97: 1648-1652.

MONTESANO, R. and ORCI, L. (1985). Tumor-promoting phorbol esters induce angiogenesis in vitro. Cel/42: 469-477.

MONTESANO, R., VASSALLI, J.D., BAIRD, A., GUILLEMIN, R. and ORCI, L. (1986). Basic fibroblast growth factor induces angiogenesis in vitro. Proc Nat/ Acad Sci USA 83: 7297-7301.

MONTESANO, R., PEPPER, M.S., MOHLE-STEINLEIN, U., RISAU, W., WAGNER, E.F. and ORCI, L. (1990). Increased proteolytic activity is responsible for the aberrant morphogenetic behavior of endothelial cells expressing the middle $T$ oncogene. Cel/62: 435-445.

MONTESANO, R., SCHALLER, G. and ORCI, L. (1991 a). Induction of epithelial tubular morphogenesis in vitro by fibroblast-derived soluble factors. Cel/ 66: 697-701.

MONTESANO, R., MATSUMOTO, K., NAKAMURA, T. and ORCI, L. (1991 b). Identification of a fibroblast-derived morphogen as hepatocyte growth factor. Cel/67: 901-908.

MONTESANO, R. and SOULIÉ P. (2002). Retinoids induce lumen morphogenesis in mammary epithelial cells. J Cel/ Sci115: 4419-4431.

MONTESANO, R., SOULIÉ, P., EBLE, J.A. and CARROZZINO, F. (2005). Tumour necrosis factor $\alpha$ confers an invasive, transformed phenotype on mammary epithelial cells. J Cel/ Sci118: 3487-3500.

MONTESANO, R. (2007 a). Bone morphogenetic protein-4 abrogates lumen formation by mammary epithelial cells and promotes invasive growth. Biochem Biophys Res Commun 353: 817-822.
MONTESANO, R., CARROZZINO, F. and SOULIÉ, P. (2007 b). Low concentrations of transforming growth factor-beta-1 induce tubulogenesis in cultured mammary epithelial cells. BMC Dev Bio/7: 7.

O'BRIEN, L.E., ZEGERS, M.P. and Mostov K.E. (2002). Building epithelial architecture: insights from three-dimensional culture models. Nat. Rev. Mol. Cell Biol. 3: $531-537$.

PEPPER, M.S., VASSALLI, J.D., MONTESANO, R. and ORCI, L. (1987). Urokinase-type plasminogen activator is induced in migrating capillary endothelial cells. J Cell Bio/105: 2535-2541.

PEPPER, M.S., FERRARA, N., ORCI, L. and MONTESANO, R. (1992a). Potent synergism between vascular endothelial growth factor and basic fibroblast growth factor in the induction of angiogenesis in vitro. Biochem Biophys Res Commun 189: 824-831.

PEPPER, M.S., MATSUMOTO, K., NAKAMURA, T., ORCI, L. and MONTESANO, R. (1992b). Hepatocyte growth factor increases ukokinase-type plasminogen activator (U-PA) and u-PA receptor expression in Madin-Darby canine kidney epithelial cells. J Biol Chem 267: 20493-20496

PEPPER, M.S., SAPPINO, A.P., STOCKLIN, R., MONTESANO, R., ORCI, L. and VASSALLI, J.D. (1993). Upregulation of urokinase receptor expression on migrating endothelial cells. J Cel/ Bio/122: 673-684.

PEPPER, M.S., VASSALLI, J.D., WILKS, J.W., SCHWEIGERER, L., ORCI, L. and MONTESANO, R. (1994). Modulation of microvascular endothelial cell proteolytic properties by inhibitors of angiogenesis. J Cell Biochem 55: 419-434.

PEPPER, M.S., SORIANO, J.V., MENOUD, P.A., SAPPINO, A.P., ORCI, L. and MONTESANO, R. (1995). Modulation of hepatocyte growth factor and c-met in the rat mammary gland during pregnancy, lactation and involution. Exp Cel/Res 219: 204-210

PEPPER, M.S., MONTESANO, R., MANDRIOTA, S.J., ORCI, L. and VASSALLI, J.D. (1996). Angiogenesis: a paradigm for balanced extracellular proteolysis during cell migration and morphogenesis. Enzyme Protein 49: 138-162.

RISAU, W. (1997). Mechanisms of angiogenesis. Nature 386: 671-674.

SORIANO, J.V., PEPPER, M.S., NAKAMURA, T., ORCI, L. and MONTESANO, R. (1995). Hepatocyte growth factor stimulates extensive development of branching duct-like structures by cloned mammary epithelial cells. J Cel/ Sci108: 413430 .

SORIANO, J.V., ORCI, L. and MONTESANO, R. (1996). TGF-beta 1 induces morphogenesis of branching cords by cloned mammary epithelial cells at subpicomolar concentrations. Biochem Biophys Res Commun 220: 879-885.

VAILHË, B., VITTET, D. and FEIGE, J.J. (2001). In vitromodels of vasculogenesis and angiogenesis. Lab. Invest. 81: 439-452.

WEIDNER, K.M., SACHS, M. and BIRCHMEIER, W. (1993). The Met receptor tyrosine kinase tranduces motility, proliferation, and morphogenetic signals of scatter factor/hepatocyte growth factor in epithelial cells. J Ce// Bio/121: 145 154

YANA, I., SAGARA, H., TAKASI, S., TAKATSU, K., NAKAMURA, K., NAKAO, K., KATSUKI, M., TANIGUCHI, S., AOKI, T., SATO, H., WEISS, S.J. and SEIKI, M. (2007). Crosstalk between neovessels and mural cells directs the site-specific expression of MT1-MMP to endothelial tip cells. J Cel/ Sci120: 1607-1614.

ZEGERS, M.M.P., O'BRIEN, L.C., YU, W., DATTA, A. and MOSTOV, K.E. (2003). Epithelial polarity and tubulogenesis in vitro. Trends Cell Biol. 13: 169-176. 


\section{Further Related Reading, published previously in the Int. J. Dev. Biol.}

See our recent Special Issue Pattern Formation edited by Cheng-Ming Chuong and Michael K. Richardson at: http://www.ijdb.ehu.es/web/contents. php?vol=53\&issue=5-6

Mechanical control of tissue morphogenesis during embryological development Donald E. Ingber

Int. J. Dev. Biol. (2006) 50: 255-266

The dynamic geometry of mass cell movements in animal morphogenesis Vladimir G. Cherdantsev

Int. J. Dev. Biol. (2006) 50: 169-182

Vasculogenesis and angiogenesis in the mouse embryo studied using quail/mouse chimeras

Michel Pudliszewski and Luc Pardanaud

Int. J. Dev. Biol. (2005) 49: 355-361

Vascular development: from precursor cells to branched arterial and venous networks Anne Eichmann, Li Yuan, Delphine Moyon, Ferdinand leNoble, Luc Pardanaud and Christiane Bréant

Int. J. Dev. Biol. (2005) 49: 259-267

The chick embryo chorioallantoic membrane as a model for in vivo research on angiogenesis.

D Ribatti, A Vacca, L Roncali and F Dammacco Int. J. Dev. Biol. (1996) 40: 1189-1197

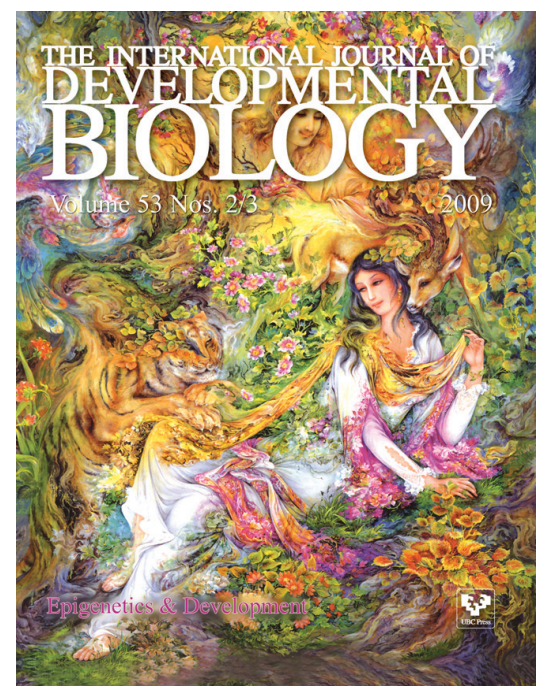

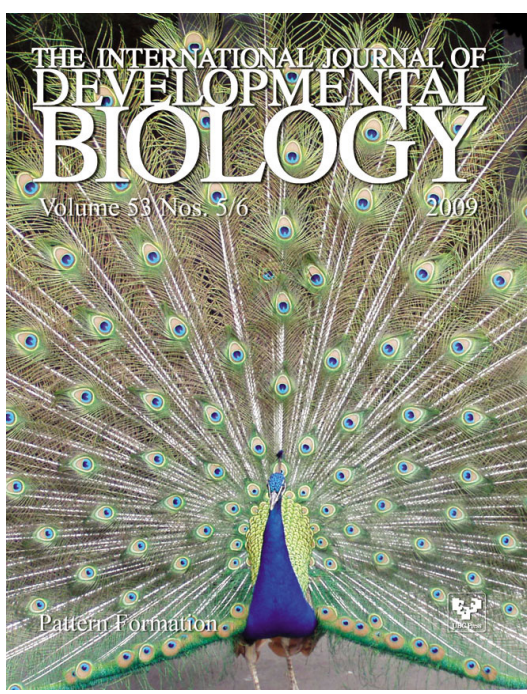

5 yr ISI Impact Factor $(2008)=3.271$

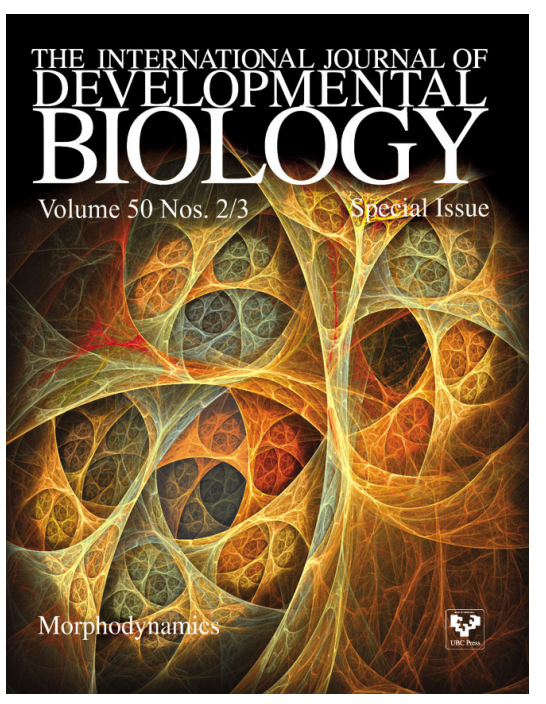

